In patients with breast cancer with overexpression of the HER2 receptor, during treatment with trastuzumab, in 30\% of cases brain metastases are observed. The use of lapatinib with capecitabine $(L+C)$ seems to be an efficacious method of curing patients in whom the spread of cancer in this location has occurred. In a patient aged 52 treated by the $L+C$ scheme a stabilization of changes in the brain was noted, lingering for 17 months. The tolerance of the treatment was good. Grade 2 hand-foot syndrome on the $\mathrm{NCl}$ 2,0 scale, nausea, a first degree increase in transaminase levels and first degree diarrhea were observed. No hematological or cardiac complications were observed.

In the third phase test comparing capecitabine with capecitabine and lapatinib in patients with advanced breast cancer, adding lapatinib to capecitabine significantly prolonged the time until progression and contributed to lessening of the amount of progression of the condition into the central nervous system. Recently published studies showed $6 \%$ remission of metastases to the central nervous system in patients with advanced breast cancer with brain metastases treated with lapatinib and $20-21 \%$ in patients receiving lapatinib with capecitabine. Future studies evaluating the effectiveness of lapatinib in patients with spread into the central nervous system should include the evaluation of lapatinib in association with cytostatics able to break through the blood-brain barrier. Lapatinib should also be tested in association with brain radiation, considering the results of preclinical studies indicating that it may work as a radiation sensitizer.

Key words: breast cancer, brain metastases, lapatinib.

\section{The possibility of lapatinib treatment for breast cancer patients with central nervous system metastases. Case study and literature review}

\author{
Janusz Rolski ${ }^{1}$, Bożenna Karczmarek-Borowska², Anetta Śmietana ${ }^{3}$
}

1Department of Clinical Oncology, Subcarpathian Oncology Centre in Rzeszów, Poland 2Oncology Unit, Department of Medicine, Rzeszów University, Poland

${ }^{3}$ Daytime Chemotherapy Department, Subcarpathian Oncology Centre in Rzeszów, Poland

\section{Introduction}

Lapatinib is a low-molecular tyrosine-kinase inhibitor, highly bound to ErbB/HER-1 and ErbB-2/HER-2 receptors of epidermal growth factor [1]. Both Her-1 and Her-2 undergo overexpression in the case of various neoplasms, including breast cancer, which represents a significant point of escape from targeted therapies. The application of trastuzumab, a monoclonal antibody targeted against the extracellular domain of the receptor, involves several difficulties. There is a possibility of the occurrence of downregulation of isoforms on surface receptors. In the process of receptor dimerization, occurring after the ligand's association with a receptor of the EGFR family, not only homodimers, but also heterodimers are formed. That is why inhibitors inhibiting selectively one tyrosine kinase at a time may not be effective in inhibiting both ErbB-1 and ErbB-2 heterodimers. Short form variants of Her-1 and Her-2, which lack extracellular domains, may occur [2, 3]. Therefore, lapatinib potentially appears to be a more effective medicine inhibiting the transfer of signals in a cell than trastuzumab, which inhibits only the extracellular activity of the Her2 receptor domain.

An interesting therapeutic field for applying lapatinib is treating brain metastases. Spread into the CNS is observed in $2.5 \%$ of patients whose breast cancer was diagnosed in the localized stage of disease, $7.6 \%$ in the case of a disease with regional metastases and $13.4 \%$ in the case of patients with initially observed spread of the disease [4-6].

In the late 1990s, soon after the introduction of trastuzumab for the treatment of patients with overexpression of the HER2 + receptor, more frequent occurrence of spread to the CNS was noted against the historical estimations [5-8].

In recent years, a retrospective analysis of 9524 patients with breast cancer participating in studies with complementary treatment conducted by the International Breast Cancer Study Group was performed. These studies were conducted before trastuzumab was introduced for complementary treatment. The studies showed that overexpression of HER2 is a risk factor for spread to the CNS. Within 10 years metastases to the CNS occurred in $6.8 \%$ of patients with HER2 overexpression in contrast to $3.5 \%(p<0.01)$ in patients without such expression [9].

It is believed that the cause of this phenomenon may be a low capability of trastuzumab to penetrate the blood-brain barrier. Because including trastuzumab for the treatment of patients with breast cancer with HER2 overexpression prolonged the life expectancy of this group of patients, it led to clinical exposure of the metastases to the CNS, which would not have manifested any symptoms in case of the patient's death $[8,10]$. 
In multivariate analysis, factors increasing the risk of the spread of breast cancer into the CNS is the young age of patients, lack of expression of hormonal receptors and diagnosis of invasive ductal carcinoma [11].

While observing this phenomenon, a possibility of curing metastatic pathological changes in the CNS with medicines targeted against the ErB-2 receptor, penetrating the bloodbrain barrier, was seen. One of the candidates for this kind of therapy is lapatinib. This conception was supported by the results of the EGF 100151 test, proving that brain metastases occurred as the first symptom of progression less frequently in the group treated with lapatinib and capecitabine than with only capecitabine - respectively $4 \%$ vs. $6 \%$, $p=0.045$ [12].

Among brain metastases resected in 123 patients in 36\% of cases expression of ErB-2 receptor was diagnosed, which is substantially more in comparison to the expression of this receptor in initial breast cancer [13].

Below a case study of a patient is presented. The patient suffered from breast cancer with overexpression of the Her2 receptor. After the trastuzumab treatment the spread of cancer occurred, among others to the CNS. The patient was successfully treated with capecitabine and lapatinib.

\section{Case description}

The patient, aged 52, noticed a tumor in the left breast in November 2003. Mammography revealed a tumor in the upper outer quadrant, $5 \times 4 \mathrm{~cm}$, with features of a malignant change. Enlarged lymphatic glands in the left armpit. Fine-needle aspiration biopsy of the left breast and the enlarged lymphatic glands in the left armpit was performed, revealing the presence of cancer cells. Breast cancer, classified T3N1MO (IIIA), was diagnosed. Clinically, at the moment of the commencement of treatment, the tumor diameter measured $7 \times 8$ $\mathrm{cm}$, left armpit lymph node diameter $3.5 \times 3.5 \mathrm{~cm}$. Considering the local advancement the patient was qualified for adjuvant chemotherapy. She received 4 cycles of treatment in the AT regimen (docetaxel $75 \mathrm{mg} / \mathrm{m}^{2}$, doxorubicin $50 \mathrm{mg} / \mathrm{m}^{2}$ ). Partial remission was obtained. In April 2004 left side Patey mastectomy was performed. Invasive ductal carcinoma was histologically diagnosed, Bloom III. Out of 13 removed lymph nodes, in one metastasis with infiltration of the lymph node capsule was found. Hormone receptors negative. In 100\% of cells strong $(+++)$ reaction to the presence of fiber cerbB2/Her-2 was identified. After the surgery the patient received 4 series of supplementary chemotherapy (cyclophosphamide - $600 \mathrm{mg} / \mathrm{m}^{2}$ day 1 and 8; 5-fluorouracil - 1000 $\mathrm{mg} / \mathrm{m}^{2}$ day 1 and 8 ; methotrexate $-40 \mathrm{mg} / \mathrm{m}^{2}$ day 1 and 8 ). Supplementary radiotherapy of the post-surgical scar and peripheral lymph nodes was applied (4500 cGy in 20 fractions).

In May 2007 in computed tomography of the abdominal cavity a tumor in the left kidney was identified. In July 2007, left-sided nephrectomy was performed, diagnosing bright cell kidney cancer of T1bNOMO clinical stage.

In the computed tomography performed in December 2007, sites of metastases were found in the liver, the biggest of them with a diameter of $21 \mathrm{~mm}$. Fine-needle aspiration biopsy confirmed the diagnosis of breast cancer metastasis. In a radiological test lung metastases were identified.
The patient was qualified for trastuzumab treatment (the first dose was $4 \mathrm{mg} / \mathrm{kg}$, the next $2 \mathrm{mg} / \mathrm{m}^{2}$ ) and vinorelbine at a dose of $30 \mathrm{mg} / \mathrm{m}^{2}$ every 7 days. The treatment was continued from January to June 2008 , achieving stabilization. In a control computed tomography test, when the progression of changes in lungs and liver was identified, AT chemotherapy, which had been successfully used in the preoperational treatment, was resumed. Five cycles of chemotherapy were applied, achieving partial remission and subsequently, due to the cumulative dosage limit of doxorubicin, the treatment was continued with docetaxel. After the first cycle of chemotherapy, due to the occurrence of head pains in December 2008, a computed tomography test was performed, which identified numerous metastases. Palliative brain radiotherapy (20 cGy in 5 fractions) was performed.

In January 2009, lapatinib treatment was commenced at a dose of $1250 \mathrm{mg} /$ day and capecitabine at a dose of 2000 $\mathrm{mg} / \mathrm{m}^{2}$ for 14 days every 3 weeks. The treatment was continued until June 2010. The treatment was disturbed by hand-foot syndrome of grade 2 on the $\mathrm{NCl}$ 2,0 scale, nausea, a first degree increase in transaminase levels and first degree diarrhea. No hematological or cardiac complications were observed. In control imaging tests stabilization of the metastases in the liver, lungs and the central nervous system was observed. In July, the patient was diagnosed with balance disorder and symptoms of left-sided hemiparesis. In brain computed tomography the progression of changes in the form of numerous metastatic changes with a diameter of 12-14 $\mathrm{mm}$ in the area of the temporal lobes, both cerebellar hemispheres and leftsided parietal region was observed. Palliative brain radiotherapy was performed again at a dose of 2000 cGy in 5 fractions. No clinical improvement was achieved. The patient died experiencing symptoms of intracranial hypertension.

\section{Overview}

By the use of lapatinib with capecitabine in a 52-year-old patient, long lasting (17 months) stability of the cancer process was achieved, including brain metastasis focal points. The result should be considered as very good, considering the fact that the average survival in patients of this group is 3 to 6 months [14].

The effectiveness of lapatinib in treating brain metastases was proved by inter-SPORE phase II trial testing. It was carried out on 39 patients, in whom metastases to the CNS occurred after the treatment with trastuzumab. 38 of the patients received previous radiotherapy. In the case of 1 patient partial regression was achieved according to the RECIST criteria, whereas in 7 (18\%) patients stabilization of the cancer process lasting longer than 16 weeks was achieved. In the case of 3 patients the volume of metastatic changes decreased by $30 \%$, in the case of 7 patients by 10-30\% [15]. The above data, although of initial character, depict that lapatinib is able to penetrate into the central nervous system and be effective in treating brain metastases.

What is more, the analysis of the registration examination of the medicine (EFG 100151) showed that lapatinib with capecitabine significantly lessens the risk of brain metastases compared to capecitabine monotherapy ( $6 \%$ vs. $2 \%, p=$ 0.045) [16]. 
In 2009, the results of a phase II study, evaluating the efficiency of lapatinib in patients with brain metastases, previously treated with trastuzumab, in whom the progression of brain changes after palliative radiotherapy was identified, were published [17]. In the case of some patients with progression during the lapatinib treatment capecitabine was added. Objective remission in the group treated with lapatinib was observed in $6 \%$ of patients. In $21 \%$ of cases a decrease of the volume of metastatic changes by $\geq 20 \%$ was observed. Better results were achieved in patients receiving lapatinib and capecitabine: $\geq 20 \%$ of objective remission and reduction of the volume of metastatic changes by $\geq 20 \%$ in $40 \%$ of patients. This may be caused by the activity of capecitabine in treating CNS metastases, previously described casuistically [18]. Additionally, earlier tests indicated certain effectiveness of capecitabine in treating brain metastases $[19,20]$.

In a study published by Ekenel et al., out of 7 patients receiving capecitabine, in 3 total remission of brain metastases was identified, whereas in 3 others stabilization occurred [20]. In Bartsch's tests clinical benefit was achieved in half of the patients with brain metastases receiving capecitabine and trastuzumab [22]. Apart from capecitabine, lapatinib may also be combined with other cytostatics penetrating the blood-brain barrier, for example temozolomide [23].

In the extended phase of the abovementioned Lin test, remission was achieved also in $20 \%$ of patients, in whom at the moment of progression of CNS metastases during the lapatinib treatment capecitabine was added [17]. It cannot be excluded that it is a result of the additive effect of both medicines, especially considering the fact that lapatinib in monotherapy does not cause many remissions in patients with advanced breast cancer. It was also observed that lapatinib with capecitabine causes remission of CNS metastases in patients previously treated with capecitabine [24].

In 2010, Suterland et al. published results of the treatment of 356 patients receiving lapatinib with capecitabine in the UK [25]. In a group of 34 patients with CNS metastases, a 21\% objective remission rate was achieved, usually accompanied by improvements of the neurological state. The median time until progression was 22 weeks. All of these observations indicate a possibility of using lapatinib in patients with brain metastases, especially those resistant to radiotherapy, because apart from treatment lowering intracranial hypertension there are no other effective options of treatment available.

Interesting results were also achieved using lapatinib with capecitabine in patients with breast cancer with HER2 expression and with brain metastases previously not radiated. The aim of the study, apart from evaluating the effectiveness and toxicity of treatment, was also the evaluation of the possibility of avoiding or postponing radiotherapy. In a group of 43 evaluated patients, objective remission of CNS metastases, defined as at least 50\% decrease in the volume of pathological changes, was observed in $67 \%$ of patients. The median time until progression was 5.5 months. This study indicates that in this group of patients this treatment can be an alternative to palliative CNS radiation [26].
Tolerance of the treatment should be evaluated as good. Side effects observed during the treatment were not severe and did not cause treatment interruption or the necessity to lower the dosage of the medications.

In conclusion, lapatinib treatment combined with capecitabine is an effective and well-tolerated therapeutic option in patients suffering from breast cancer with expression of cerbB2/HER2 fiber and CNS metastases and failure after radiotherapy.

Lapatinib should also be tested in association with brain radiation, bearing in mind the results of preclinical studies indicating that it may work as a radiation sensitizer.

The authors declare no conflict of interest.

\section{References}

1. Gaul MD, Guo Y, Affleck K, et al. Discovery and biological evaluation of potent dual ErbB-2/EGFR tyrosine kinase inhibitor: $\mathrm{G}$ - thiazolylguinazolines. Bioorg Med Chem Lett 2003; 13: 637-40.

2. Reid $A$, Vidal L, Shaw $H$, de Bono J. Dual inhibition of ErbB1 (EGFR/HER1) and ErbB2 (Her2/neu). Eur J Cancer 2007; 43: 481-9.

3. Xia W, Liu LH, Ho P, Spector NL. Truncated ErbB2 receptor (p95ErbB2) is regulated by heregulin through heterodimer formation with ErbB3 yet remains sensitive to the dual EGFR/ErbB2 kinaze inhibitor GW572016. Oncogene 2004; 23: 646-53.

4. Barnholtz-Sloan JS, Sloan AE, Davis FG, Vigneau FD, Lai P, Sawaya RE. Incidence proportions of brain metastases in patients diagnosed (1973 to 2001) in the Metropolitan Detroit Cancer Surveillance System. J Clin Oncol 2004; 22: 2865-72.

5. Lin NU, Bellon JR, Winer EP. CNS metastases in breast cancer. J Clin Oncol 2004; 22: 3608-17.

6. Tsukada Y, Fouad A, Pickren JW, Lane WW. Central nervous system metastasis from breast carcinoma. Autopsy study. Cancer 1983; 52: 2349-54.

7. Altaha R, Crowell E, Hobbs G, Higa G, Abraham J. Risk of brain metastases in HER2/neu positive breast cancer. J Clin Oncol 2004; 22: $22-47$.

8. Clayton AJ, Danson S, Jolly S, et al. Incidence of cerebral metastases in patients treated with trastuzumab for metastatic breast cancer. Br J Cancer 2004; 91: 639-43.

9. Pestalozzi BC, Zahrieh D, Price KN, et al.; International Breast Cancer Study Group (IBCSG). Identifying breast cancer patients at risk for Central Nerwous System (CNS) metastases in trials of the International Breast Cancer Study Group (IBCSG). Ann Oncol 2006; 17: 935-44.

10. Heinrich B, Brudler O, Siekiera W, et al. Development of brain metastases in metastatic breast cancer (MBC) responding to treatment with trastuzumab (abstract 147). Proc Am Soc Clin Oncol 2003; 22: 37.

11. Tham YL, Sexton K, Kramer R, Hilsenbeck S, Elledge R. Primary breast cancer phenotypes associated with propensity for central nervous system metastases. Cancer 2006; 107: 2521-2.

12. Cameron D, Casey M, Press M, et al. A plase III randomized comparison of lapatynib and capecitabine versus capecitabine alone in woman with advanced breast cancer that has progressed on trastuzumab: updated efficacy and biomarker analysis. Breast Cancer Res Treat 2008; 112: 533-43.

13. Palmieri D, Bronder JL, Herring JM, et al. Her-2 overexpression increases the metastatic outgrowth of breast cancer cells in the brain. Cancer Res 2007; 47: 4190-8.

14. Mahmoud-Ahmed AS, Suh JH, Lee SY, Crownover RL, Barnett GH. Results of whole brain radiotherapy in patients with brain metastases from breast cancer: a retrospective study. Int I Radiat Oncol Biol Phys 2002; 54: 810-7.

15. Lin NU, Carey LA, Liu MC, et al. Phase II trial of lapatinib for brain metastases in patients with human epidermal growth factor receptor 2-positive breast cancer. J Clin Oncol 2008; 26: 1993-9. 
16. Geyer CE, Forster J, Lindquist D, et al. Lapatynib plus capecytabine for HER2 - positive advanced breast cancer. N Engl J Med 2006; 355: 2733-43.

17. Lin NU, Diéras V, Paul D, et al. Multicenter phase II study of lapatynib in patients with brain metastases from HER2 - positive breast cancer. Clin Cancer Res 2009; 15: 1452-9.

18. Wang ML, Yung WK, Royce ME, Schomer DF, Theriault RL. Capecitabine for 5-fluorouracil-resistant brain metastases from breast cancer. Ann J Clin Oncol 2001; 24: 421-4.

19. Tham YL, Hinckley L, Teh BS, Elledge R. Long-term clinical response in laptomeningeal metastases from breast cancer treated with capecytabine monotherapy: a case report. Clin. Breast Cancer 2006; 7: 164-6.

20. Ekenel M, Hormigo AM, Peak S, Deangelis LM, Abrey LE. Capecitabine therapy of central nervous system metastases from breast cancer. J Neurooncol 2007; 85: 223-7.

21. Hikino H, Yamada T, Johbara K, Obayashi N, Ozaki N. Potential role of chemoradiation with oral capecitabine in a breast cancer patient with central nerwous system relapse. Breast 2006; 15: 97-9.

22. Bartsch R, Wenzel C, Altorjai G, et al. Capecitabine and trastuzumab in heavily pretreated metastatic breast cancer. J Clin Oncol 2007; 25: 3853-8.

23. Rivera E, Meyers C, Groves M, et al. Phase I study of capecitabine in combination with temozolomide in the treatment of patients with brain metastases from breast carcinoma. Cancer 2006; 107: 1348-54.

24. Boccardo F, Kaufman B, Baselga J, et al. Evaluation of lapatynib plus capecytabine in subjects with brain metastases from HER2+ breast cancer envolled in the Lapatynib Expanded Access Program (LEAP) and French Authorisation Temporaive Utilisation. J Clin Oncol 2008; 26: 20 Suppl.

25. Sutherland S, Ashley S, Miles D, et al. Treatment of HER2 - positive metastatic breast cancer with lapatynib and capecitabine in the lapatynib expanded access programme, including efficacy in brain metastases - the UK experience. Br J Cancer 2010; 102: 995-1002.

26. Bachelot TD, Romieu G, Campone M, et al. LANDSCAPE: An FNCLCC phase II study with lapatinib $(L)$ and capecytabine $(C)$ in patients with brain metastases (BM) from HER2-positive (+) metastatic breast cancer (MBC) before whole-brain radiotherapy (WBR). J Clin Oncol 2011; 29: Suppl. [Abstract 509].

27. Zhou H, Kim YS, Peletier A, McCall W, Earp HS, Sartor Cl. Effects of the EGFR/HER2 kinase inhibitor GW572016 on EGFR- and HER2-overexpressing breast cancer cell line proliferation, radiosensitization, and resistance. Int J Radiat Oncol Biol Phys 2004; 58: 344-52.

\section{Address for correspondence}

\section{dr n. med. Janusz Rolski}

Oddział Onkologii Klinicznej

Podkarpackie Centrum Onkologii w Rzeszowie

ul. Szopena 2

35-055 Rzeszów

e-mail: janusz_rolski@wp.pl

Submitted: $\quad 9.06 .2011$

Accepted: $\quad 26.01 .2012$ 